\title{
Could public policies reduce inequalities in physical activity and health?
}

\section{Billie Giles-Corti}

The global burden of disease due to physical inactivity is substantial equating to around 366 deaths each hour due to physical inactivity. The burden is so large that recently there have been calls to rethink our approach to physical activity promotion $^{1}$, with growing recognition of the need to engage city planners to create cities and local communities that support active living.

The idea that city planning might enhance health isn't new. At the turn of last century, city planning was successfully used to protect residents of rapidly industrialising overcrowded and polluted cities in the United States, the United Kingdom and Australia. Infectious disease outbreaks plummeted with the provision of clean water and sanitation, land use zoning that separated polluting industries from residential development; and regulations establishing minimum housing lot sizes.

However, in the $21^{\text {st }}$ century, city planning is now needed to tackle chronic diseases, the rise of which threatens global social and economic development growth ${ }^{2}$. Creating cities that support physically active lifestyles - walking, cycling and public transport use - is consistent with the United Nation's Sustainable Development Goals ${ }^{3}$ and never more urgent, given rapid population growth and urbanisation ${ }^{4}$. Transitioning cities to support lifestyles that are both 'healthy for individuals and for the planet', is therefore a priority climate mitigation strategy ${ }^{5}$ with co-benefits for health and health equity.

A fast body of evidence from across the globe now shows that if we build it, they will come $e^{6,7}$. Higher density, mixed use development with connected street networks, accessible local destinations and public transport, are consistently shown to encourage walking for transport. Brazilian research is consistent with the international literature. Reis et al. ${ }^{8}$ found that the odds of walking for transport was twice as high in residents of high rather than low walkable neighbourhoods, and the odds of leisure time MVPA was 60\% higher.

Yet, like many rapidly developing countries, motor vehicle ownership in Brazil is skyrocketing increasing by $172 \%$ in the decade up to 2013 . This has important implications for the health and wellbeing of Brazilians. Studies consistent show that time-spent driving (including driving to work) is associated with weight gain $^{9,10}$, with evidence from China showing that in men (but not women), the adjusted odds of obesity doubled in households which gained a motor vehicle ${ }^{11}$.

Is motor vehicle dependence inevitable? Isn't this simply an external sign of 'progress' in countries in response to economic growth? Not really: fostering motor vehicle dependency is a choice, influenced by federal, state and local 
government policies, and motor vehicle dependency are not inevitable. In many advanced developed European economies - Denmark, the Netherlands, Germany - a commitment to policies and infrastructure investments supporting walking, cycling and public transport use - has seen increases walking and cycling trips as form of transportation, with these modes the most frequent even in adults over 75 years ${ }^{12}$. Not surprisingly therefore, countries with the highest proportion of walking, cycling and public transport trips, enjoy lower levels of obesity and vice versa ${ }^{13}$.

However, cities that prioritize walking, cycling and public transport, commit to investing in pedestrian and cycling infrastructure and public transport, and policies supporting creation of accessible communities rather than the simply focussing on motor vehicle mobility. Creating attractive accessible higher density walkable neighbourhoods well served by public transport with connected street networks, local destinations, human scale, traffic management and natural surveillance - both day and night - encourages more people to walk, which in turn creates walking environments that feel (and are) safer because there are more 'eyes of the street ${ }^{14}$. However, in countries with hot climates such as Brazil (and indeed Australia), there is also a need for shade to be provided by creating buildings with awnings and tree plantings

So why is there such a large gap between research and policy and practice? In the face of mounting evidence to the contrary, why is it that we continue to build cities prioritising motor vehicles over pedestrians, cyclists and public transport users. More importantly, how do we close the gap between researchers, policymakers and practitioners? And how do we close the gap between what we know, and what is implemented?

These questions were the subject of a recently published review ${ }^{15}$. In this review we concluded that if active living academics want their research to be used by policymakers it must be 'policy-relevant'. Asking policy-relevant questions doesn't mean the research isn't innovative or cutting-edge. Rather the questions, asked resonate with the issues being confronted by policy-makers and practitioners. Amongst other things, this can only be achieved if researchers: (1) have more contact with policy-makers and practitioners; (2) understand the policy-world they are attempting to change; (3) establish joint research agendas, and (4) work with knowledge-brokers and advocates to help diffuse and disseminate their findings.

Across the globe, there are successful examples where academics are doing this ${ }^{16}$, from which we can all learn and apply elsewhere. In Australia, for example, for decades researchers have worked with the Heart Foundation (a knowledge broker and advocate) to help write evidence-based policy to inform its advocacy work $^{17}$; establish evidence-based on-line guidance (see Healthy Active by Design http://www.healthyactivebydesign.com.au/); and contribute to state ${ }^{18-20}$; and Federal ${ }^{21,22}$ policies and reports by responding to calls for submissions, providing evidence at public inquiries and contributing evidence to inform policies.

So is there a role for evidence to inform policies that could reduce inequities? Most definitely: evidence - particularly geographic information systems data can be used to benchmark and compare within and between cities to identify what WHO calls 'hidden cities' i.e., areas where there are inequities ${ }^{23}$. It can then be used to monitor progress over time and also to evaluate policy interventions. Increasingly in Australia ${ }^{24,25}$, we are taking data that typically sits on our computers, to provide maps that can be used by the community and local and state government to design interventions. In Victoria, we are fortunate to have Community Indicators 
Victoria (see http://www.communityindicators.net.au/) which not only provides data but also training and consultancy services to local government to assist them to use data to inform their municipal health and wellbeing plans. This is a major knowledge translation mechanism, that could be modified and applied elsewhere.

Returning to the title of my paper: Could public policies reduce inequities in physical and activity and health? Indeed they could: however to be effective, policies need to be evidence-informed and evaluated to monitor the level of implementation ${ }^{26}$ and their impact. Clearly, active living researchers potentially have an important role to play. However, if we want to produce evidence with the potential to creates equitable cities that promote active living, we must not only undertake cutting-edge high quality research, we must also leave the academy and work directly with the communities which we serve. The job is large, and it is not necessarily easy. However, for health, sustainability and equity it is important. The question for each of us has to ask ourselves, is: am I up to the challenge and willing to come out of the academy to contribute?

\section{References}

1. Das P, Horton R. Rethinking our approach to physical activity. Lancet. 2012; 380(9838):189-90.

2. United Nations. Sixty seventh session Political Declaration of the High Level meeting of the General Assembly on the Prevention and control of non-communicable diseases. 2011. http://www.un.org/ga/search/view_doc.asp?symbol=A/66/L.1.

3. United Nations. Open working group proposal for Sustainable Development Goals. New York: United Nations, 2014.

4. United Nations Population Fund. State of world population 2010. . New York: UNFPA, 2011.

5. Watts N, Adger WN, Agnolucci P, et al. Health and climate change: policy responses to protect public health. Lancet. 2015.

6. Moran M, Van Cauwenberg J, Hercky-Linnewiel R, Cerin E, Deforche B, Plaut P. Understanding the relationships between the physical environment and physical activity in older adults: a systematic review of qualitative studies. Int J Behav Nutr Phys Act. 2014;11:79.

7. Hajna S, Ross NA, Brazeau AS, Belisle P, Joseph L, Dasgupta K. Associations between neighbourhood walkability and daily steps in adults: a systematic review and metaanalysis. BMC Public Health. 2015;15(1):768.

8. Reis RS, Hino AAF, Rech CR, Kerr J, Hallal PC. Walkability and Physical Activity Findings from Curitiba, Brazil. Am J Prev Med. 2013; 45(3): 269-75.

9. Sugiyama T, Ding D, Owen N. Commuting by car: weight gain among physically active adults. Am J Prev Med. 2013;44(2):169-73.

10. Frank LD, Andresen MA, Schmid TL. Obesity relationships with community design, physical activity, and time spent in cars. Am J Prev Med. 2004;27(2):87-96.

11. Bell AC, Ge K, Popkin BM. The road to obesity or the path to prevention: motorized transportation and obesity in China. Obes Res. 2002;10(4):277-83.

12. Pucher J, Dijkstra L. Promoting safe walking and cycling to improve public health: lessons from The Netherlands and Germany. Am J Public Health. 2003; 93(9): 1509-16.

13. Bassett DRJ, Pucher J, Buehler R, Thompson DL, Crouter SE. Walking, cycling, and obesity rates in Europe, North America, and Australia. J Phys Act Health. 2008; 5(6): 795-814.

14. Foster S, Knuiman M, Wood L, Giles-Corti B. Suburban neighbourhood design: Associations with fear of crime versus perceived crime risk. J Environ Psychol. 2013;36:112-7.

15. Giles-Corti B, Sallis JF, Sugiyama T, Frank LD, Lowe M, Owen N. Translating active living research into policy and practice: One important pathway to chronic disease prevention. J Public Health Policy. 2015; 36(2): 231-43.

16. Pratt M, Perez LG, Goenka S, et al. Can population levels of physical activity be increased? Global evidence and experience. Prog Cardiovasc Dis. 2015; 57(4): 356-67. 
17. National Heart Foundation of Australia. Blueprint for an active Australia. 2nd edition. Melbourne.: National Heart Foundation of Australia, 2014.

18. Legislative Council Environment and Planning References Committee. Inquiry into environmental design and public health in Victoria. Melbourne, Victoria: Government Printer for the State of Victoria, 2012.

19. State of Victoria. Plan Melbourne - Metropolitan Planning Strategy. In: Department of Transport PaLI, editor. Treasury Place, Melbourne: Victorian Government; 2014.

20. Western Australian Planning Commission. Liveable neighbourhoods: A Western Australian Government Sustainable Cities initiative. Perth, 2000.

21. Giles-Corti B, Eagleson S, Lowe M. Securing Australia's Future - Sustainable Urban Mobility. The public health impacts of transportation decisions. Melbourne: Consultancy Services, 2014.

22. Department of Infrastructure and Transport. Our cities, our future. A national urban policy for a productive, sustainable and liveable future. Canberra: Department of Infrastructure and Transport, 2011.

23. World Health Organization, Habitat U. Hidden cities: Unmasking and overcoming health inequities in urban settings. Geneva: World Health Organization, 2010.

24. Badland H, Roberts R, Butterworth I, Giles-Corti B. How liveable is Melbourne? Conceptualising and testing urban liveablity indicators. Melb.: University of Melbourne, 2015.

25. Giles-Corti B, Mavoa S, Eagleson S, Davern M, Roberts R, Badland H. How walkable is Melbourne? The development of a transport walkability index for Metropolitan Melbourne. Melb.: University of Melbourne, 2014.

26. Hooper P, Giles-Corti B, Knuiman M. Evaluating the implementation and active living impacts of a state government planning policy designed to create walkable neighborhoods in perth, Western Australia. Am J Health Promot. 2014; 28(3 Suppl): S5-S18. 